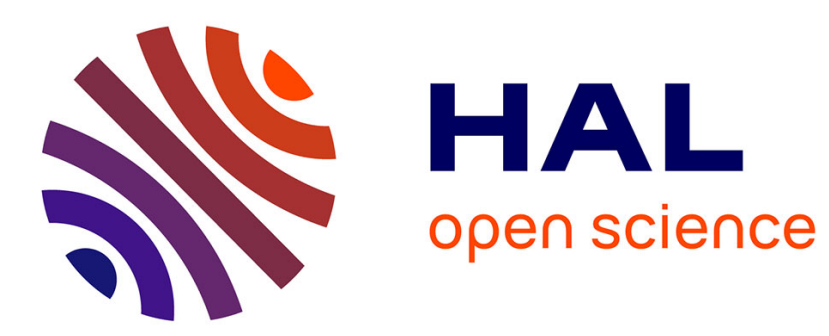

\title{
Synthesis of single-walled carbon nanotube-Co-MgO composite powders and extraction of the nanotubes
}

Emmanuel Flahaut, Alain Peigney, Christophe Laurent, Abel Rousset

\section{To cite this version:}

Emmanuel Flahaut, Alain Peigney, Christophe Laurent, Abel Rousset. Synthesis of single-walled carbon nanotube-Co-MgO composite powders and extraction of the nanotubes. Journal of Materials Chemistry, 2000, vol. 10, pp. 249-252. 10.1039/a908593i . hal-00942779

\section{HAL Id: hal-00942779 \\ https://hal.science/hal-00942779}

Submitted on 6 Feb 2014

HAL is a multi-disciplinary open access archive for the deposit and dissemination of scientific research documents, whether they are published or not. The documents may come from teaching and research institutions in France or abroad, or from public or private research centers.
L'archive ouverte pluridisciplinaire $\mathbf{H A L}$, est destinée au dépôt et à la diffusion de documents scientifiques de niveau recherche, publiés ou non, émanant des établissements d'enseignement et de recherche français ou étrangers, des laboratoires publics ou privés. 


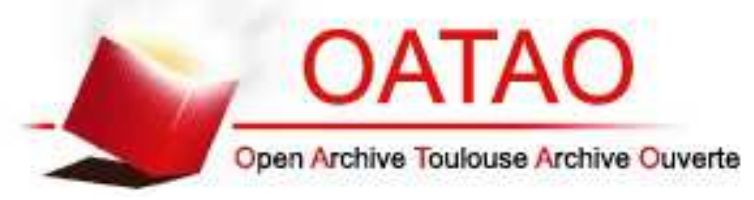

\section{Open Archive TOULOUSE Archive Ouverte (OATAO)}

OATAO is an open access repository that collects the work of Toulouse researchers and makes it freely available over the web where possible.

This is an author-deposited version published in : http://oatao.univ-toulouse.fr/ Eprints ID : 10892

To link to this article : DOI:10.1039/a908593i

URL : http://dx.doi.org/10.1039/a908593i

\section{To cite this version :}

Flahaut, Emmanuel and Peigney, Alain and Laurent, Christophe and Rousset, Abel Synthesis of single-walled carbon nanotube-Co-MgO composite powders and extraction of the nanotubes. (2000) Journal of Materials Chemistry, vol. 10 ( $\mathrm{n}^{\circ}$ 2). pp. 249-252. ISSN 0959-9428

Any correspondance concerning this service should be sent to the repository administrator: staff-oatao@ listes-diff.inp-toulouse.fr 


\title{
Synthesis of single-walled carbon nanotube-Co-MgO composite powders and extraction of the nanotubes
}

\author{
E. Flahaut, A. Peigney, Ch. Laurent* and A. Rousset \\ Laboratoire de Chimie des Matériaux Inorganiques, ESA CNRS 5070, Université \\ Paul-Sabatier, 31062 Toulouse cedex 4, France.E-mail: laurent@iris.ups-tlse.fr
}

\begin{abstract}
A carbon nanotube-Co-MgO composite powder is prepared by reducing a $\mathrm{Mg}_{0.9} \mathrm{Co}_{0.1} \mathrm{O}$ solid solution in $\mathrm{H}_{2}-\mathrm{CH}_{4}$ atmosphere. The oxide matrix and part of the Co catalyst are dissolved by acid treatment without damage to the nanotubes. More than $80 \%$ of the carbon nanotubes have either one or two walls. The diameters of the nanotubes are in the range $0.5-5 \mathrm{~nm}$. The utilized method may be a real improvement in the low-cost, large-scale synthesis of single- and double-walled carbon nanotubes.
\end{abstract}

Catalytic methods may be efficient for the low-cost, large-scale production of carbon nanotubes. In previous work, the present laboratory ${ }^{1-3}$ has reported the synthesis of composite powders containing well dispersed carbon nanotubes by selective reduction in $\mathrm{H}_{2}-\mathrm{CH}_{4}$ of oxide solid solutions between a nonreducible oxide such as $\mathrm{Al}_{2} \mathrm{O}_{3}$ or $\mathrm{MgAl}_{2} \mathrm{O}_{4}$ and one or more transition metal oxide(s). The reduction produces very small transition metal ( $\mathrm{Fe}, \mathrm{Co}, \mathrm{Ni}$ and their alloys) nanoparticles at a temperature of usually $>800{ }^{\circ} \mathrm{C}$. The decomposition of $\mathrm{CH}_{4}$ over the freshly formed nanoparticles prevents their further growth which results in a very high proportion of single-walled carbon nanotubes (SWNTs) and small multiwalled carbon nanotubes (MWNTs) compared to other forms of carbon. High resolution electron microscopy (HREM) observations indicate that the active catalyst particles for the formation of carbon nanotubes are below $6 \mathrm{~nm}$ in diameter. ${ }^{3}$ Dense ceramic-matrix composites containing carbon nanotubes have been prepared from such powders. ${ }^{4}$

Other researchers ${ }^{5-8}$ have prepared SWNTs by catalytic decomposition of carbon monoxide or hydrocarbons on metal nanoparticles supported on $\mathrm{Al}_{2} \mathrm{O}_{3}$ or $\mathrm{SiO}_{2}$. Cassell et al. ${ }^{7}$ notably reported that their best results were obtained by using a new $\mathrm{Al}_{2} \mathrm{O}_{3}-\mathrm{SiO}_{2}$ hybrid material. However, in these materials, ${ }^{1-3,5-8}$ the carbon nanotubes are obtained as a mixture with the metal oxide catalyst, which may be detrimental to future applications. In contrast, Cheng et al. ${ }^{9}$ prepared ropes of SWNT bundles by decomposition of ferrocene-thiophene-benzene-hydrogen mixtures but they report the presence of impurities such as carbon nanoparticles, catalyst particles and carbon blacks on the surfaces of or among the bundles, thus requiring some purification. In this communication, we report the synthesis of a carbon nanotube$\mathrm{Co}-\mathrm{MgO}$ powder by a solid solution method and the extraction of the carbon nanotubes by a mild acid treatment that does not damage them.

A $\mathrm{Mg}_{0.9} \mathrm{Co}_{0.1} \mathrm{O}$ solid solution was prepared by combustion synthesis ${ }^{10}$ of a stoichiometric mixture of the metal nitrates and urea. The total combustion process is complete in $<5$ min and one combustion batch yields $c a .6 \mathrm{~g}$ of oxide powder. $1.5 \mathrm{~g}$ of this powder was placed in a furnace under a flowing $\mathrm{H}_{2}-\mathrm{CH}_{4}$ mixture $\left(18 \mathrm{~mol} \% \quad \mathrm{CH}_{4}, 250 \mathrm{sccm}\right)$ and was heated at $1000^{\circ} \mathrm{C}$. After reaching this temperature, the powder was cooled in $\mathrm{H}_{2}$; heating and cooling rates were $5{ }^{\circ} \mathrm{C} \mathrm{min}{ }^{-1}$. The so-obtained carbon nanotube- $\mathrm{Co}-\mathrm{MgO}$ composite powder was studied using X-ray diffraction (XRD) and scanning electron microscopy (SEM). The carbon content was determined by flash combustion. The powder was submitted to treatment in $\mathrm{HCl}$ aqueous solution ( $36 \%$, room temperature) in order to extract the carbon nanotubes by dissolution of $\mathrm{MgO}$ and part of the Co. The resulting product was washed with deionised water and air dried overnight at room temperature. It was studied by XRD, transmission electron microscopy (TEM), thermogravimetric analysis (TGA) and differential thermogravimetric analysis (DTG). The carbon content was determined by flash combustion.

The carbon content in the composite powder was found to be $6.0 \mathrm{wt} \%$. Analysis of the XRD pattern revealed the presence of $\varepsilon$-Co in addition to the $\mathrm{MgO}$ matrix. Peaks corresponding to carbonaceous material were not detected. SEM observations (Fig. 1) revealed that the metal oxide grains, $c a .300 \mathrm{~nm}$ in size, are uniformly entrapped in a web-like network of very long (tens or even hundreds of micrometers), flexible filaments showing extensive branching. Most filaments are $<20 \mathrm{~nm}$ in diameter. TEM studies of similar materials ${ }^{1-3}$ have revealed that such filaments are bundles of carbon nanotubes.

The composite powder was submitted to treatment with $\mathrm{HCl}$ solution which led to a blue colour indicating the formation of a cobalt complex after dissolution of some cobalt particles. The XRD pattern of the obtained solid showed the peaks of $\varepsilon$-Co and a peak corresponding to the (002) reflection that could correspond to both graphite and carbon nanotubes. $\mathrm{MgO}$ peaks were not detected, showing that the matrix was totally dissolved. The remaining cobalt corresponds to particles that were not dissolved owing to the presence of surrounding graphene layers, as shown by HREM observations. The carbon content in this product was found to be $64.4 \mathrm{wt} \%$ (i.e. 90 atom $\%$ ). TGA in flowing air showed that the weight gains corresponding to the oxidation of $\mathrm{Co}$ to $\mathrm{Co}_{3} \mathrm{O}_{4}$ (DTG peaks at 210 and $>245^{\circ} \mathrm{C}$ ) and the weight loss corresponding to the oxidation of carbon (DTG peak at $310^{\circ} \mathrm{C}$ ) partly overlap,

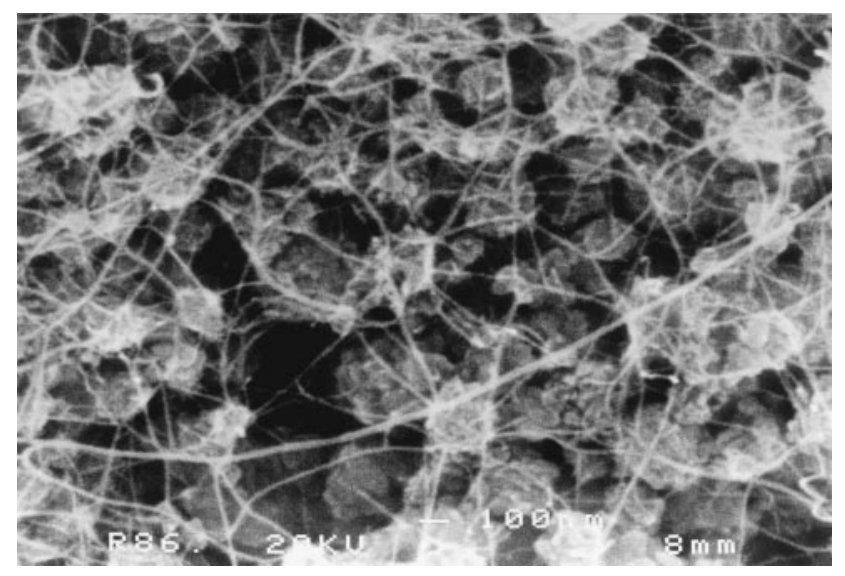

Fig. 1 SEM image of the carbon nanotube-Co- $\mathrm{MgO}$ composite powder. 

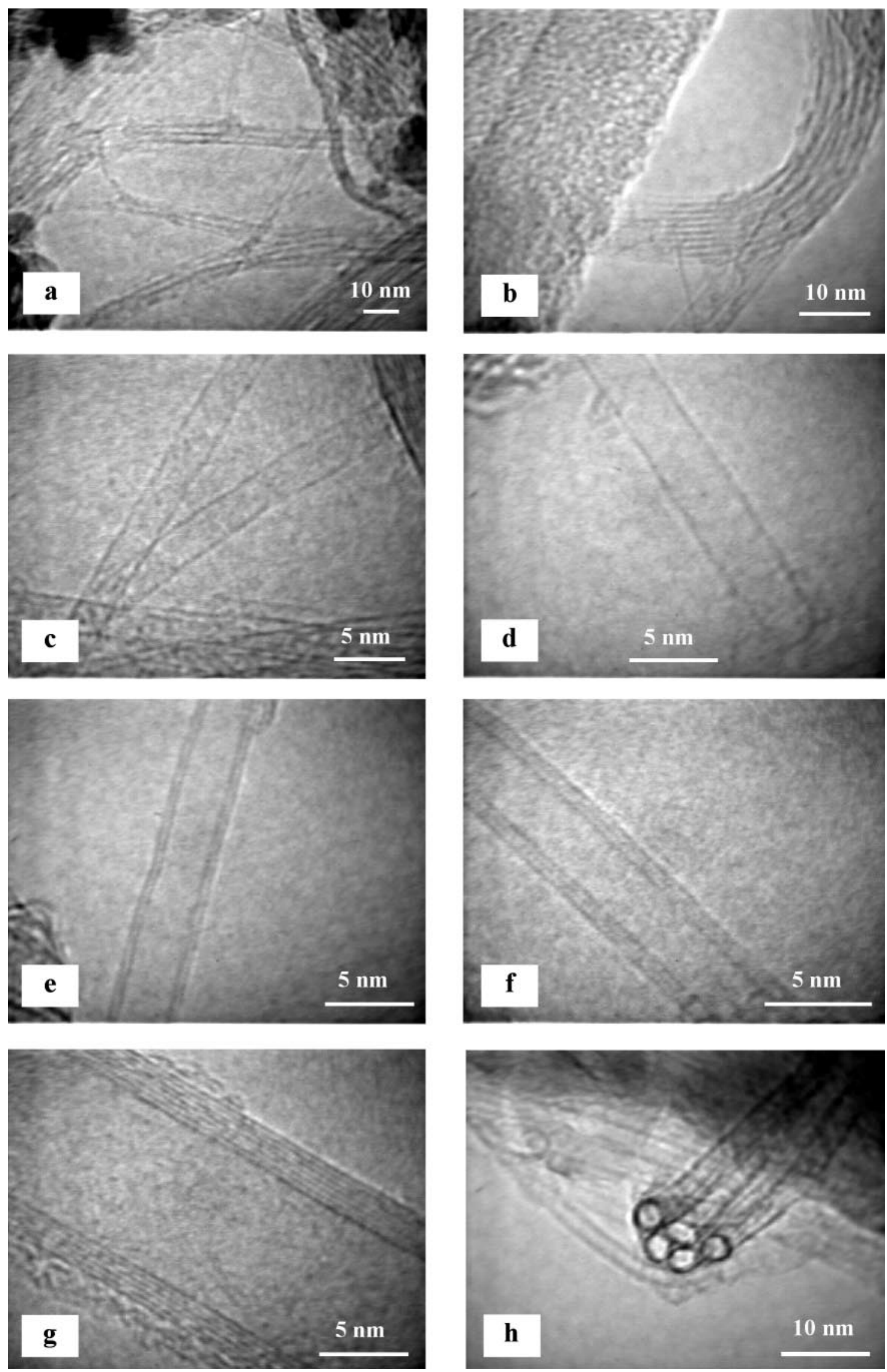

Fig. 2 HREM images of the carbon nanotubes obtained after $\mathrm{HCl}$ treatment: (a) individual carbon nanotubes emerging out of small bundles; (b) bundles of 8.2 and $6.5 \mathrm{~nm}$ diameter (the left part of the image shows the grid); (c) SWNTs of 2.4 and $2.6 \mathrm{~nm}$ diameter; (d) an SWNT of $3.2 \mathrm{~nm}$ diameter with a particle-free closed hemispheric tip; (e) a nanotube with two walls; (f) a nanotube with three walls; (g) one of the largest observed MWNTs, with an internal diameter of $c a .8 .3 \mathrm{~nm}$. There are seven walls on one side and only six walls on the other with amorphous carbon present on the tube surface; this may result from the degradation of the nanotube under the electron beam; (h) a bundle of five nanotubes, SWNTs or DWNTs, arranged in a triangular packing. 
making it difficult to assess the carbon content. However, a weight loss at $918^{\circ} \mathrm{C}$ that corresponds to the formation of $\mathrm{CoO}$ from the previously formed $\mathrm{Co}_{3} \mathrm{O}_{4}$ particles allows calculation of the amount of residual cobalt in the specimen and so the carbon content can be deduced. The value thus obtained $(64.5 \mathrm{wt} \%)$ is in line with that obtained by flash combustion. Work on the extraction and purification of the carbon nanotubes is in progress and will be reported elsewhere.

TEM observations reveal that the extracted product consists of a mixture of carbon nanotubes and catalyst particles. Carbon is essentially found as nanotubes, either isolated or gathered in bundles and as graphene sheets surrounding the catalyst particles. The observed nanotubes were found to be undamaged by the mild acid treatment. HREM observations were carried out on isolated carbon nanotubes and typical images are presented in Fig. 2. The extensive merging of carbon nanotubes into bundles is illustrated in Fig. 2(a). The diameter of the bundles shown in Fig. 2(b) are 8.2 and $6.5 \mathrm{~nm}$ (the left part of the image shows the grid). Although SWNTs with a diameter as small as $0.8 \mathrm{~nm}$ have been observed, most have a larger diameter, as do those observed in Fig. 2(c) (2.4 and $2.6 \mathrm{~nm})$ and Fig. 2(d) $(3.2 \mathrm{~nm})$. The latter SWNT has a closed hemispheric tip with no catalyst particle at the tip. However, in some cases a catalyst particle was found attached to the tube end. These features are characteristics of 'base-growth' and 'tip-growth' mechanisms, respectively ${ }^{1-13}$ and thus they both could be operative under the present experimental conditions, assuming no modification of the sample during preparation for TEM examination. Other researchers using the catalytic method have reported either 'base-growth" ${ }^{6,7}$ or 'tip-growth" mechanisms.

Some MWNTs with a small number of walls (Fig. 2(e), two walls and Fig. 2(f), three walls) were also observed. Fig. 2(g) shows one of the largest observed MWNT, with an internal diameter of $c a .8 .3 \mathrm{~nm}$. There are seven walls on one side of the tube [upper side in Fig. 2(g)] but only six walls on the other side. In addition, amorphous carbon is present on the tube surface. Since amorphous carbon deposits are scarcely observed in the present materials, it is inferred that this is a consequence of degradation of the nanotube under the electron beam. It is also noteworthy that pyrolytic thickening of the nanotubes did not occur under the present experimental conditions. Fig. 2(h) shows a bundle of five nanotubes arranged in a triangular packing. The nanotubes are SWNTs or DWNTs and their average diameter is $3 \mathrm{~nm}$.

The number of walls as well as the inner and outer diameters of 80 isolated nanotubes were measured from HREM images similar to those shown in Fig. 2. More than $80 \%$ of the nanotubes have only one or two walls, about half of these being SWNTs [Fig. 3(a)]. This proportion is lower than that reported by Hafner et al. ${ }^{6}$ for nanotubes prepared by passing $\mathrm{C}_{2} \mathrm{H}_{4}$ over supported $\mathrm{Fe} / \mathrm{Mo}$ particles at $700^{\circ} \mathrm{C}(70 \%)$, but higher than that obtained at $850{ }^{\circ} \mathrm{C}(30 \%)$. Cassell et al. ${ }^{7}$ reported that the proportion of DWNTs is negligible in their specimens. Most internal and external diameters are in the range $0.5-5 \mathrm{~nm}$ [Fig. 3(b)], which is a much larger distribution than those reported for nanotubes prepared by arc-discharge, ${ }^{14-16}$ laservaporization, ${ }^{17,18}$ and hydrocarbon-ferrocene decomposition. ${ }^{9}$ However, the distribution is in good agreement with other results obtained by the catalysis method..$^{5-8}$ More than $90 \%$ of the present carbon nanotubes have a diameter of $<3 \mathrm{~nm}$, which is in excellent agreement with the theoretical and experimental results reported by Hafner et al. ${ }^{6}$ However, SWNTs with diameters $>3 \mathrm{~nm}$ are observed, which suggests that catalytic particles slightly $>3 \mathrm{~nm}$ can also be active, as opposed to becoming onionated. ${ }^{6}$ Large diameter nanotubes could be interesting for applications such as hydrogen absorption. ${ }^{19}$ In contrast to other results, ${ }^{6}$ some DWNTs have a lower inner diameter than most SWNTs. This may indicate that at least some tubes are formed by the so-called
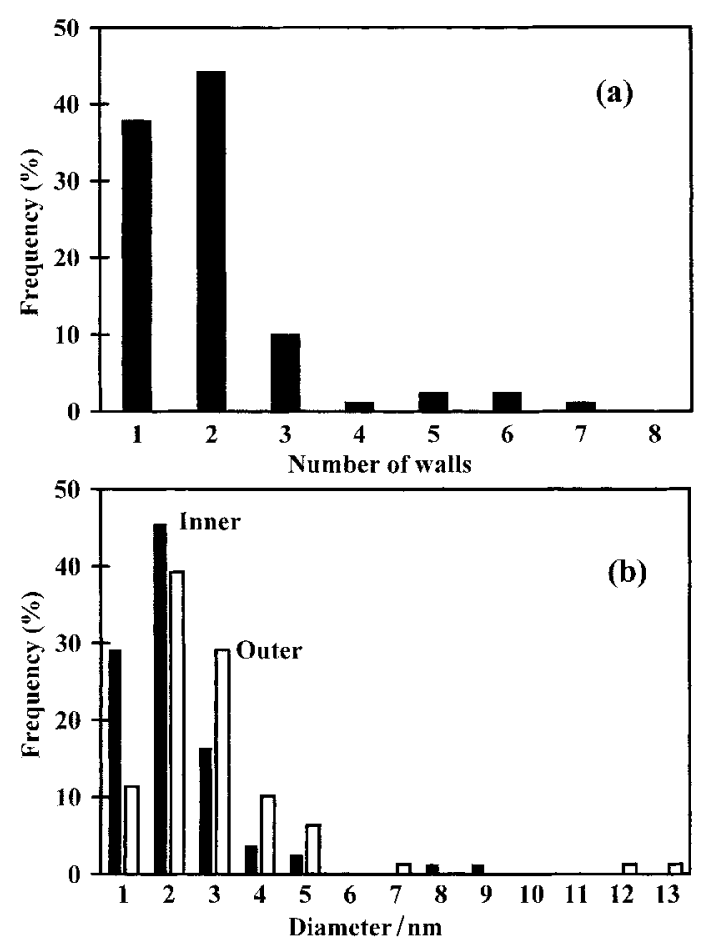

Fig. 3 Distribution of the number of walls (a) and of the inner and outer diameters (b) of the carbon nanotubes using data from HREM images.

yarmulke mechanism, ${ }^{5}$ a characteristic of which is that the outer wall is formed first.

Chen et al. ${ }^{20}$ have prepared MWNTs from $\mathrm{CH}_{4}$ decomposition and $\mathrm{CO}$ disproportionation on a $\mathrm{Ni}-\mathrm{MgO}$ powder derived from the $\mathrm{H}_{2}$ reduction of a $\mathrm{Mg}_{0.6} \mathrm{Ni}_{0.4} \mathrm{O}$ solid solution. The quantity of starting material is very small $(12 \mathrm{mg} c f .6 \mathrm{~g}$ in the present work). The obtained MWNTs are $15-20 \mathrm{~nm}$ in diameter, in sharp contrast with the present results. This arises owing to important experimental differences, besides the use of cobalt instead of nickel: first we use a much lower amount of transition metal ( $x=0.1 c f$. 0.4$)$, second the present reduction is performed in $\mathrm{H}_{2}-\mathrm{CH}_{4}$ with no prior treatment in $\mathrm{H}_{2}$, thus preventing a premature growth of the catalyst particles.

These results confirm that only metal particles smaller than $c a$. $6 \mathrm{~nm}$ catalyse the formation of carbon nanotubes and underline the requirement that the catalyst is in the form of such nanoparticles at a temperature, usually above $600{ }^{\circ} \mathrm{C}$, used in the catalysis methods. The reduction of oxide solid solutions allows the production of metal particles at a high enough temperature for the hydrocarbon gas to interact with them so as to form the nanotubes prior to any significant particle growth. In contrast, materials derived from the impregnation of a substrate by a transition metal salt usually consist of large carbon fibres, some of which are hollow, only a small proportion of which are true carbon nanotubes (see Rodriguez $^{21}$ for a review). This can be overcome only by using a refractory metal such as $\mathrm{Mo}^{5}$ and $\mathrm{Fe} / \mathrm{Mo}^{6,7}$ or a small metal catalyst loading. ${ }^{8}$

In conclusion, we have demonstrated the ability to prepare carbon nanotube- $\mathrm{Co}-\mathrm{MgO}$ composite powders by reducing a $\mathrm{Mg}_{0.9} \mathrm{Co}_{0.1} \mathrm{O}$ solid solution in $\mathrm{H}_{2}-\mathrm{CH}_{4}$ atmosphere. The nanotubes are well dispersed owing to their formation in situ. It has also been shown that the oxide matrix and part of the Co catalyst can be dissolved by a mild acid treatment that does not damage the nanotubes which was not possible when using oxide matrices such as $\mathrm{Al}_{2} \mathrm{O}_{3}$ and $\mathrm{MgAl}_{2} \mathrm{O}_{4} \cdot{ }^{1-3}$ This represents a strong advantage for the possibilities offered by the 'solid-solution' method. More than $80 \%$ of the carbon nanotubes have either one or two walls with diameters in the 
range $0.5-5 \mathrm{~nm}$. The proposed method could be a real improvement in the low-cost, large-scale synthesis of singleand double-walled carbon nanotubes.

The authors thank Mr. L. Datas for his assistance in the HREM observations, which have been performed at the Service Commun de Microscopie Electronique à Transmission, Université Paul-Sabatier.

\section{Notes and references}

1 A. Peigney, Ch. Laurent, F. Dobigeon and A. Rousset, J. Mater. Res., 1997, 12, 613.

2 E. Flahaut, A. Govindaraj, A. Peigney, Ch. Laurent, A. Rousset and C. N. R. Rao, Chem. Phys. Lett., 1999, 300, 236.

3 A. Peigney, Ch. Laurent and A. Rousset, J. Mater. Chem., 1999, 9, 1167.

4 Ch. Laurent, A. Peigney and A. Rousset, J. Eur. Ceram. Soc., 1998, 18, 2005.

5 H. Dai, A. G. Rinzler, P. Nikolaev, A. Thess, D. T. Colbert and R. E. Smalley, Chem. Phys. Lett., 1996, 260, 471.

6 J. H. Hafner, M. J. Bronikowski, B. K. Azamian, P. Nikolaev, A. G. Rinzler, D. T. Colbert, K. A. Smith and R. E. Smalley, Chem. Phys. Lett., 1998, 296, 195.

7 A. M. Cassell, J. A. Raymakers, J. Kong and H. Dai, J. Phys. Chem., 1999, 103, 6484.
8 J.-F. Colomer, G. Bister, I. Willems, Z. Konya, A. Fonseca, G. Van Tendeloo and J. B. Nagy, Chem. Commun., 1999, 1343.

9 H. M. Cheng, F. Li, X. Sun, S. D. M. Brown, M. A. Pimenta, A. Marucci, G. Dresselhaus and M. S. Dresselhaus, Chem. Phys. Lett., 1998, 289, 602.

10 K. C. Patil, Bull. Mater. Sci., 1993, 16, 533.

11 G. G. Tibbetts, M. G. Devour and E. J. Rodda, Carbon, 1987, 25, 367.

12 R. T. K. Baker, Carbon, 1989, 27, 315.

13 S. Amelinckx, X. B. Zhang, D. Bernaerts, X. F. Zhang, V. Ivanov and J. B. Nagy, Science, 1994, 265, 635.

14 S. Iijima and T. Ichihashi, Nature (London), 1993, 363, 603

15 S. Seraphin and D. Zhou, Appl. Phys. Lett., 1994, 64, 2087.

16 C. Journet, W. K. Maser, P. Bernier, A. Loiseau, M. Lamy de la Chapelle, S. Lefrant, P. Deniard, R. Lee and J. E. Fisher, Nature (London), 1997, 388, 756.

17 A. Thess, R. Lee, P. Nikolaev, H. Dai, P. Petit, J. Robert, C. Xu, Y. H. Lee, S. G. Kim, A. G. Rinzler, D. T. Colbert, G. E. Scuseria, D. Tomanek, J. E. Fisher and R. E. Smalley, Science, 1996, 273, 483.

18 T. Guo, P. Nikolaev, A. Thess, D. T. Colbert and R. E. Smalley, Chem. Phys. Lett., 1995, 243, 49.

19 A. C. Dillon, K. M. Jones, T. A. Bekkedahl, C. H. Kiang, D. S. Bethune and M. J. Heben, Nature (London), 1997, 386, 377.

20 P. Chen, H. B. Zhang, G. D. Lin, Q. Hong and K. R. Tsai, Carbon, 1997, 35, 1495.

21 N. M. Rodriguez, J. Mater. Res., 1993, 8, 3233. 